\title{
Hepatoid adenocarcinoma of the lung: report of five cases and review of the literature
}

\author{
Diana M Haninger ${ }^{1}$, Goetz H Kloecker², Michael Bousamra II ${ }^{3}$, Michael R Nowacki ${ }^{4}$ and \\ Stephen P Slone ${ }^{1}$
}

${ }^{1}$ Department of Pathology and Laboratory Medicine, University of Louisville School of Medicine, Louisville, KY, USA; ${ }^{2}$ Department of Medicine, Division of Medical Oncology and Hematology, University of Louisville School of Medicine, Louisville, KY, USA ${ }^{3}$ Department of Surgery, University of Louisville School of Medicine, Louisville, KY, USA and ${ }^{4}$ Pathology and Laboratory Medicine, Norton Hospital, Louisville, KY, USA

\begin{abstract}
The current diagnostic criteria for hepatoid adenocarcinoma of lung include typical acinar or papillary adenocarcinoma and a component resembling hepatocellular carcinoma and expressing $\alpha$-fetoprotein (AFP). Distinguishing hepatoid adenocarcinoma of lung from hepatocellular carcinoma metastatic to lung is difficult in patients with both lung and liver masses and in patients at risk for lung and liver cancer because of smoking and viral hepatitis, respectively. We studied morphologic features of hepatoid adenocarcinoma of lung and established an immunohistochemical panel to facilitate distinction of hepatoid adenocarcinoma of lung from hepatocellular carcinoma metastatic to lung. Five cases of hepatoid adenocarcinoma of lung were stained with hematoxylin and eosin and mucicarmine for histomorphologic evaluation. The 14-marker immunohistochemical profile was established for hepatoid adenocarcinoma of lung and compared with that of hepatocellular carcinoma. Two cases of hepatoid adenocarcinoma of lung had signet-ring cell components. Three cases were pure hepatoid adenocarcinoma without components of acinar or papillary adenocarcinoma, signet-ring cells or neuroendocrine carcinoma. Like hepatocellular carcinoma, hepatoid adenocarcinoma of lung expresses CK8 (5/5), CK18 (5/5), AFP (3/5) and HepPar1 (5/5), shows cytoplasmic staining with TTF-1 (5/5) and does not express CK14 (0/5). Unlike hepatocellular carcinoma, it expresses CK5/6 (1/5), CK7 (3/5), CK19 (4/5), CK20 (1/5), HEA125 $(5 / 5)$, MOC31 (5/5), monoclonal CEA (3/5) and napsin A (1/5). An immunohistochemical panel that includes a variety of cytokeratins, monoclonal CEA and EPCAM markers (HEA125 and MOC31) facilitates distinction of hepatoid adenocarcinoma of lung from hepatocellular carcinoma metastatic to lung, especially when correlated with clinical and radiologic findings. We propose modification of the current diagnostic criteria for hepatoid adenocarcinoma of lung. Tumor composition can be either pure hepatoid adenocarcinoma or hepatoid adenocarcinoma with components of typical acinar or papillary adenocarcinoma, signet-ring cells or neuroendocrine carcinoma. AFP expression is not requisite for diagnosis as long as other markers of hepatic differentiation are expressed.

Modern Pathology (2014) 27, 535-542; doi:10.1038/modpathol.2013.170; published online 13 September 2013
\end{abstract}

Keywords: $\alpha$-fetoprotein; hepatoid adenocarcinoma; immunohistochemistry; liver; lung

Hepatoid adenocarcinoma is a rare extrahepatic tumor with morphologic features similar to hepatocellular carcinoma. Metzgeroth et al ${ }^{1}$ reviewed the literature and summarized the clinical findings of 261 cases of hepatoid adenocarcinoma. The most common site of origin for hepatoid adenocarcinoma is stomach (63\%). Other sites of origin include ovary

Correspondence: Dr DM Haninger, DO, Department of Pathology and Laboratory Medicine, University of Louisville School of Medicine, 530S Jackson Street, Louisville, KY 40202, USA.

E-mail: dohani01@louisville.edu

Received 13 June 2013; revised 31 July 2013; accepted 1 August 2013; published online 13 September 2013
(10\%), lung (5\%), gallbladder (4\%), pancreas $(4 \%)$ and uterus $(4 \%)$.

Ishikura et $a l^{2}$ studied five cases of primary pulmonary adenocarcinoma with $\alpha$-fetoprotein (AFP) expression. They coined the term hepatoid adenocarcinoma of lung and adopted two criteria for diagnosis: (1) typical acinar or papillary adenocarcinoma and (2) a component of carcinoma that resembles hepatocellular carcinoma and produces AFP.

Lung is one of the least common sites of origin for hepatoid adenocarcinoma. There are only 16 case reports of hepatoid adenocarcinoma of lung in the literature (Table 1). ${ }^{3-17}$ Anatomic pathologists 
Table 1 Histomorphologic features of lung hepatoid adenocarcinoma and hepatocellular carcinoma

\begin{tabular}{lcc}
\hline Morphology & $\begin{array}{c}\text { Hepatoid } \\
\text { adenocarcinoma }\end{array}$ & $\begin{array}{c}\text { Hepatocellular } \\
\text { carcinoma }\end{array}$ \\
\hline $\begin{array}{l}\text { Hyaline globules } \\
\text { Bile plugs }\end{array}$ & $2 / 5$ & Present \\
Pale bodies & $0 / 5$ & Present \\
& $0 / 5$ & Present \\
\hline
\end{tabular}

should be cognizant of this rare tumor to avoid confusion with metastatic hepatocellular carcinoma. We report four male patients and one female patient with hepatoid adenocarcinoma of lung, modify the diagnostic criteria of Ishikura et $a l^{2}$ and discuss an immunohistochemical panel to distinguish hepatoid adenocarcinoma of lung from hepatocellular carcinoma metastatic to lung.

\section{Materials and methods}

\section{Case Selection}

After securing IRB approval from the University of Louisville Medical Center and the James Graham Brown Cancer Center (Louisville, KY, USA), archival surgical pathology specimens from the following cases were retrieved and analyzed using the methods outlined as follows.

\section{Case Histories}

Case 1. The patient, a 51-year-old white male smoker (45 pack years), had clinical history of hepatitis C and tuberculosis. He sought medical consultation for cough and congestion and was treated with antibiotics and solumedrol without resolution of symptoms. Outpatient chest X-ray suggested the presence of a lung mass. PET/CT scan confirmed a $4.3 \times 3.0 \mathrm{~cm}^{2}$ necrotic mass in the right paratracheal region adjacent to a $4.2 \times 3.7 \mathrm{~cm}^{2}$ necrotic right parahilar mass that occluded the right upper lobe bronchus and narrowed the bronchus intermedius. There were metastases to mediastinal and right supraclavicular nodes. There were no hepatic mass lesions. Clinical stage was IIIB (T2a, $\mathrm{N} 3$ and M0). Bronchoscopy for endobronchial tumor debridement cleared the right main stem bronchus. Several large fragments of tumor were sent to pathology. Serum AFP level before chemoradiation therapy was not obtained. Post-treatment AFP level was $1.3 \mathrm{ng} / \mathrm{ml}$ (normal $<7.5 \mathrm{ng} / \mathrm{ml}$ ). Post-treatment bronchoscopy showed that the right main stem bronchus was patent. He died of disease 14 months after presentation.

Case 2. The patient, a 52-year-old white male smoker (40 pack years), had clinical history of emphysema, alcoholism and hepatitis C. While hospitalized for otitis externa, he complained of right lower quadrant pain, headaches, hearing loss, paresthesias and loss of balance. CT scan showed tumors in the right adrenal gland $(8.0 \mathrm{~cm})$, right frontal lobe $\left(2.6 \times 2.0 \mathrm{~cm}^{2}\right)$, right posterior cerebellum $\left(2.3 \times 1.7 \mathrm{~cm}^{2}\right)$ and pole of the right upper lobe of lung $(2.5 \mathrm{~cm})$. There were no hepatic mass lesions. There was no mediastinal, retroperitoneal or abdominal adenopathy. Clinical stage was IV (Tlb, NO and M1b). Right adrenalectomy and wedge resection of lung were performed. The patient was treated with postoperative chemoradiation therapy. Pre- and post-treatment AFP levels were not obtained. The patient is alive 37 months after presentation.

Case 3. The patient, a 64-year-old white male smoker (75 pack years), had clinical history of emphysema and degenerative disc disease. Family history was significant for lung cancer. His mother and sister were non-smokers, but both women died of lung cancer. His brother smoked and died of lung cancer. The patient sought medical consultation after he palpated a left neck mass. CT scan showed a partially necrotic mass $\left(5.5 \times 3.5 \times 3.2 \mathrm{~cm}^{3}\right)$ involving the left half of the $\mathrm{C} 2$ vertebral body. There was a spiculated mass $\left(3.2 \times 2.2 \mathrm{~cm}^{2}\right)$ in the left upper lobe of lung. There were neither hepatic masses nor adenopathy. Clinical stage was IV (pT2a, NO and M1b). He underwent posterior transpedicular resection of the paraspinal tumor and received postoperative chemoradiation therapy. Pretreatment AFP level was not obtained. Post-treatment AFP level was $1 \mathrm{ng} / \mathrm{ml}$. Epidermal growth factor receptor (EGFR) mutation study was negative. Restaging whole-body PET scan detected metastatic disease in the dome of the liver $(1.0 \mathrm{~cm})$. The patient died of disease 10 months after presentation.

Case 4. The patient, a 54-year-old white female smoker (35 pack years), sought medical consultation for pain that localized to the lower left sternal border. Chest CT scan showed a $1.0 \mathrm{~cm}$ nodule in the apex of the left upper lobe and a $5.0 \times 4.0 \mathrm{~cm}^{2}$ mass at the fifth costosternal junction. Biopsy of the costosternal mass revealed metastatic adenocarcinoma of the lung. Clinical stage was IV (pT1a, No and M1b). She was treated with chemoradiation therapy with complete resolution of the costosternal metastasis. The patient did well until 4 years later when she relapsed with bilateral lung metastases and right frontal skull bone metastasis. She had an objective response to a second round of chemoradiation therapy and did well until 4 years later when she appeared chronically ill for the first time with disease progression. PET/CT scan revealed metastases to mediastinal lymph nodes and pericardium. Bronchoscopy showed tumor involving the carina with extension into the proximal medial wall of the left main stem bronchus with $80 \%$ occlusion of the 
lumen. Endobronchial tumor debridement to clear the occlusion was followed by radiation to the left main stem bronchus and chemotherapy. Patient is alive 9 years after presentation.

Case 5. The patient, a 60-year-old white male smoker (40 pack years), had clinical history of emphysema, cough, unintentional weight loss and muscle spasms in his right arm and hand and right side of face. There was no clinical history of cirrhosis. He consulted a chiropractor for pain deep to the right shoulder blade. Chest X-ray revealed a large mass in the right upper lobe. Subsequent PET/ CT scan showed a solid heterogeneously enhancing multilobulated mass $\left(11.2 \times 10.1 \times 8.5 \mathrm{~cm}^{3}\right)$ in the superior segment of the right upper lobe. There was metastatic disease to subcarinal lymph node $\left(2.5 \times 1.5 \mathrm{~cm}^{2}\right)$ and probable metastatic disease to conglomerated right perihilar lymph nodes $(4.8 \times$ $3.3 \mathrm{~cm}^{2}$ ) with focal dense calcifications likely due to remote granulomatous disease. There were no hepatic mass lesions. Head CT scan showed a $2.3 \mathrm{~cm}$ mass in the left parietal lobe. Brain biopsy revealed metastatic hepatoid adenocarcinoma of lung. Clinical stage was IV (pT3, N2 and M1b). Pretreatment AFP level was $4410 \mathrm{ng} / \mathrm{ml}$.

\section{Histological and Immunohistochemical Analysis}

Tissue sections, $5 \mu \mathrm{m}$ thick, were cut from formalinfixed, paraffin-embedded archival surgical specimens for hematoxylin and eosin, mucicarmine and immunohistochemical stains. Immunohistochemical stains for CK8, CK14 and CK18 were carried out via an avidin-biotin conjugate (ABC) method with an automated stainer (Autostainer; Dako, Carpenteria, CA, USA) and a commercial peroxidase-conjugated streptavidin-biotin detection system (LSAB2; Dako). Immunohistochemical stains for CK5/6, CK7, CK19, CK20, AFP, HepPar1, TTF-1, napsin A, HEA125, MOC31, CEA (monoclonal), $\beta$-isoform of estrogen receptor (ER $\beta$ ), ALK 1 (D5F3) and Ki-67 were performed on an automated stainer (BOND-MAX; Leica Microsytems, Bannockburn, IL, USA) and a commercial Bond polymer detection system (Leica Microsystems). All immunohistochemical stains were carried out with appropriate positive and negative controls.

\section{Immunohistochemical Scores for Estrogen Receptors}

The Allred immunohistochemical score (intensity score plus proportion score) for estrogen receptor expression was calculated in a semiquantitative manner. ${ }^{18}$ The proportion score was dependent on the proportion of tumor cells with positive staining: 0 , none; $1,<1 / 100 ; 2,1 / 100$ to $1 / 10 ; 3,1 / 10$ to $1 / 3$; $4,1 / 3$ to $2 / 3$; and $5,>2 / 3$. The intensity score was assigned according to staining intensity: 0, none; 1, weak; 2, intermediate; and 3 , strong. Intensity score and proportion score were added together for a combined immunohistochemical score: negative (0), weak (2-4) and strong (5-8).

\section{Results}

Three cases were pure hepatoid adenocarcinoma of the lung without components of acinar or papillary adenocarcinoma, signet-ring cells or neuroendocrine carcinoma. Two cases had signet-ring cell components. Cell borders were distinct and cytoplasm was abundant and lightly acidophilic (Figure 1). Patterns of growth varied from diffuse to nodular and trabecular. Three cases showed moderate nuclear pleomorphism and two cases exhibited marked nuclear pleomorphism with multinucleation, nuclear windows and acidophilic macronucleoli. Chromatin was vesicular. Cytoplasmic hyaline globules were present in two cases (Figure 2). There were no bile plugs or pale bodies (Table 1). Lymphoplasmacytic infiltrates localized to both stroma and tumor parenchyma (Figure 3). There were variable amounts of tumor necrosis in four cases. Three cases had low mitotic counts $\left(<1,1\right.$ and $1-2$ mitotic figures per $\left.\mathrm{mm}^{2}\right)$, whereas the two pleomorphic cases had high mitotic counts (7 and 10 mitotic figures per $\mathrm{mm}^{2}$ ).

The immunohistochemical profiles of hepatoid adenocarcinoma of lung and hepatocellular carcinoma are summarized in Table 2. A variety of cytokeratins were expressed by hepatoid adenocarcinoma of the lung: CK5/6 (1/5), CK7 (3/5), CK8 (5/5), CK18 (5/5), CK19 (4/5) and CK20 (1/5). There was no expression of CK14 (0/5). AFP was expressed in $3 / 5$ cases (Figure 4). Napsin A was expressed in 1/5 cases. HepPar 1, HEA125 and MOC31 were expressed in 5/5 cases. TTF-1 staining appeared

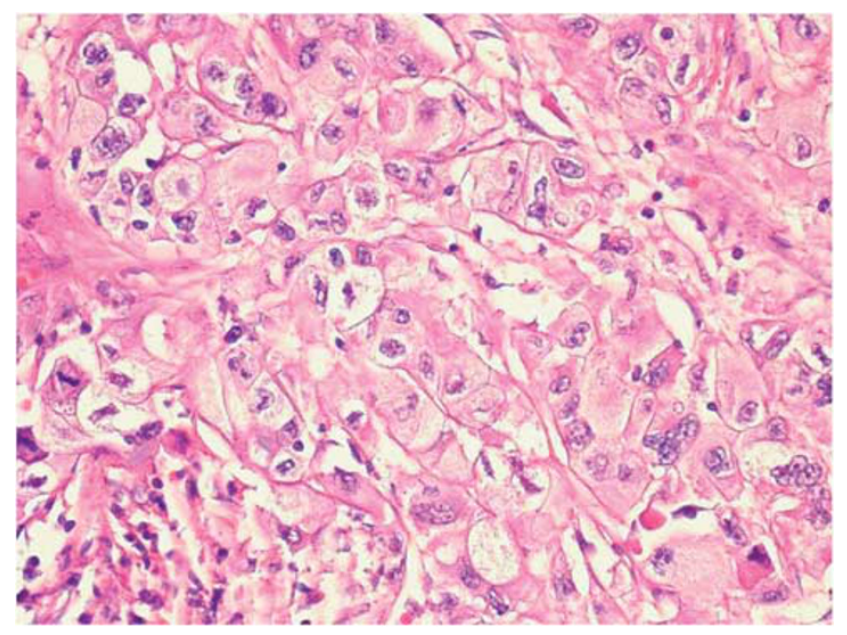

Figure 1 Hepatoid adenocarcinoma of the lung has morphologic features remarkably similar to hepatocellular carcinoma. Note the distinct cell borders and abundant lightly acidophilic cytoplasm (hematoxylin and eosin, $\times 40$ ). 


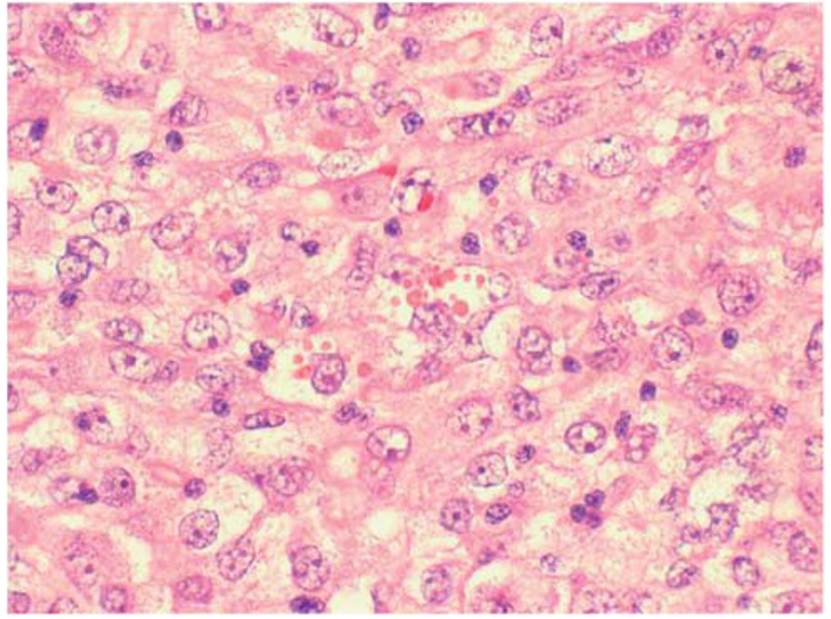

Figure 2 Cytoplasmic hyaline globules were present in two of four cases ( hematoxylin and eosin, $\times 60$ ).

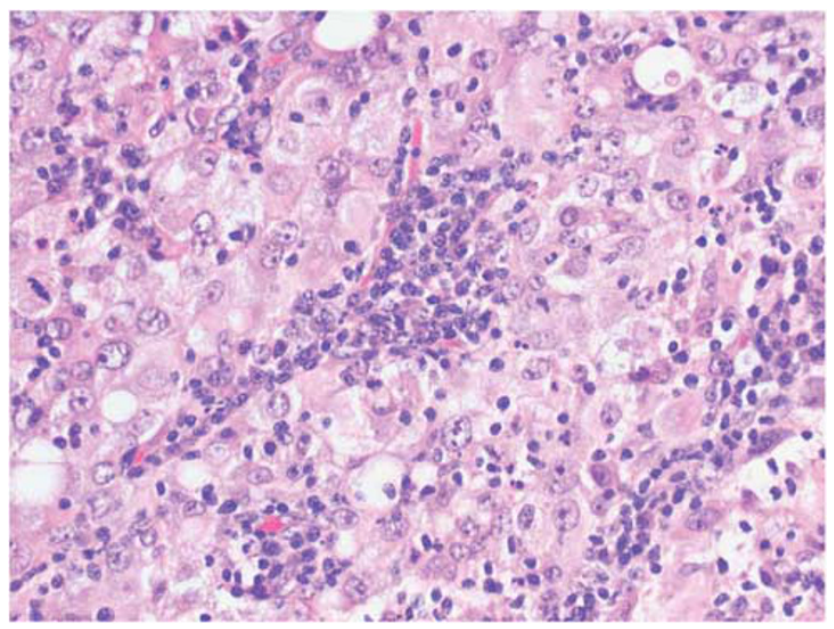

Figure 3 Lymphoplasmacytic infiltrates localized to stroma and tumor parenchyma ( hematoxylin and eosin, $\times 40$ ).

granular and localized to the cytoplasm in 5/5 cases (Figure 5). Monoclonal CEA immunostains localized to the cytoplasm and membrane in $3 / 5$ cases. Allred immunohistochemical scores for ER $\beta$ were weak in four cases and strong in one case. Although signetring cells (Figure 6) were present in $2 / 5$ cases, immunohistochemical stains for ALK 1 were negative $(0 / 5)$.

Mitotic counts and proliferative indices were concordant in all five cases. Three cases with low mitotic counts $(<1,1$ and $1-2$ mitotic figures per $\mathrm{mm}^{2}$ ) had low proliferative indices (Ki-67 scores: $10 \%$ each case), whereas both pleomorphic cases with high mitotic counts $(7$ and 10 mitotic figures per $\mathrm{mm}^{2}$ ) had high proliferative indices (Ki-67 scores: $50 \%$ and $30 \%$, respectively).
Table 2 Immunohistochemical profiles of current cases of lung hepatoid adenocarcinoma and those typically found in hepatocellular carcinoma

\begin{tabular}{lcl}
\hline Stain & $\begin{array}{c}\text { Hepatoid } \\
\text { adenocarcinoma }\end{array}$ & $\begin{array}{l}\text { Hepatocellular } \\
\text { carcinoma }\end{array}$ \\
\hline CK5/6 & $1 / 5$ & Negative \\
CK7 & $3 / 5$ & Negative \\
CK8 & $5 / 5$ & Positive \\
CK14 & $0 / 5$ & Negative \\
CK18 & $5 / 5$ & Positive \\
CK19 & $4 / 5$ & Negative \\
CK20 & $1 / 5$ & Negative \\
AFP & $3 / 5$ & Positive \\
HepPar1 & $5 / 5$ & Positive \\
TTF-1 (cytoplasmic) & $5 / 5$ & Positive \\
HEA 125 & $5 / 5$ & Negative \\
MOC31 & $5 / 5$ & Negative \\
CEA & $3 / 5$ & Negative \\
ER $\beta$ & $5 / 5^{\mathrm{a}}$ & Not typically performed \\
ALK 1 & $0 / 5$ & Negative \\
Napsin A & $1 / 5$ & Negative \\
\hline
\end{tabular}

${ }^{\text {a} A l l r e d ~ s c o r e s: ~} 4$, weak; 1 , strong.

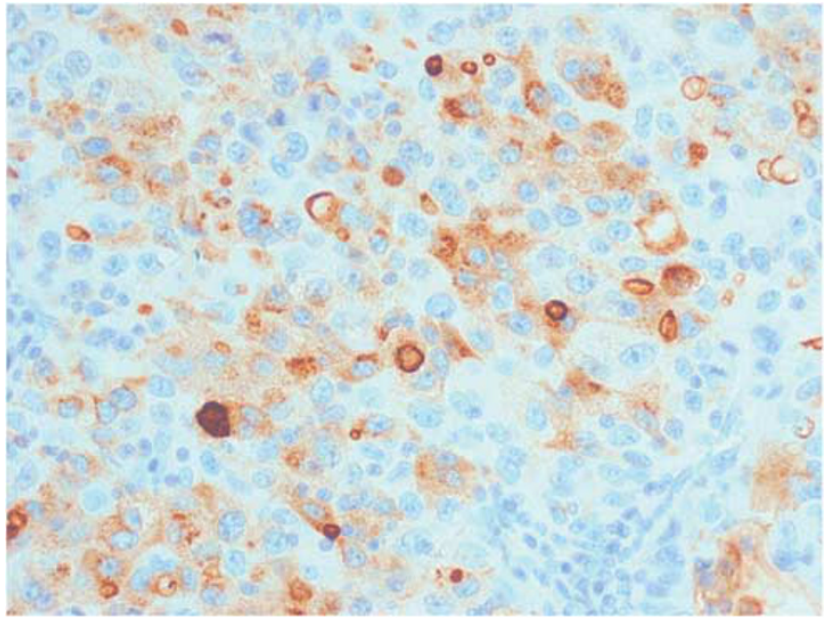

Figure $4 \alpha$-Fetoprotein (AFP) localized to the cytoplasm in two of four cases $(\times 40)$.

\section{Discussion}

There are 16 case reports of hepatoid adenocarcinoma of lung in the world literature (Table 3). ${ }^{3-17}$ All 16 patients were men with large lung tumors. The majority of patients presented with advanced stage disease. Stage progression was common and prognosis was poor, with the exception of a stage IB patient who was disease free 7 years after presentation. Smoking history was only provided in four cases, but all four patients were heavy smokers. The clinical features of the current patients with hepatoid adenocarcinoma of the lung are similar to prior accounts in the literature. Four patients were heavy smoker men and one patient was a heavy 


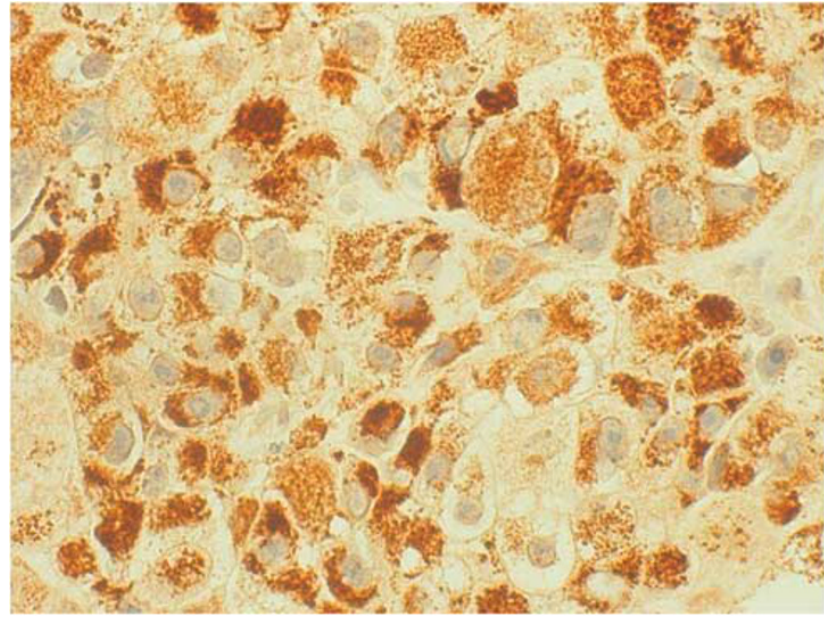

Figure 5 Transcription factor-1 (TTF-1) localized to the cytoplasm in hepatoid adenocarcinoma of the lung $(\times 40)$.

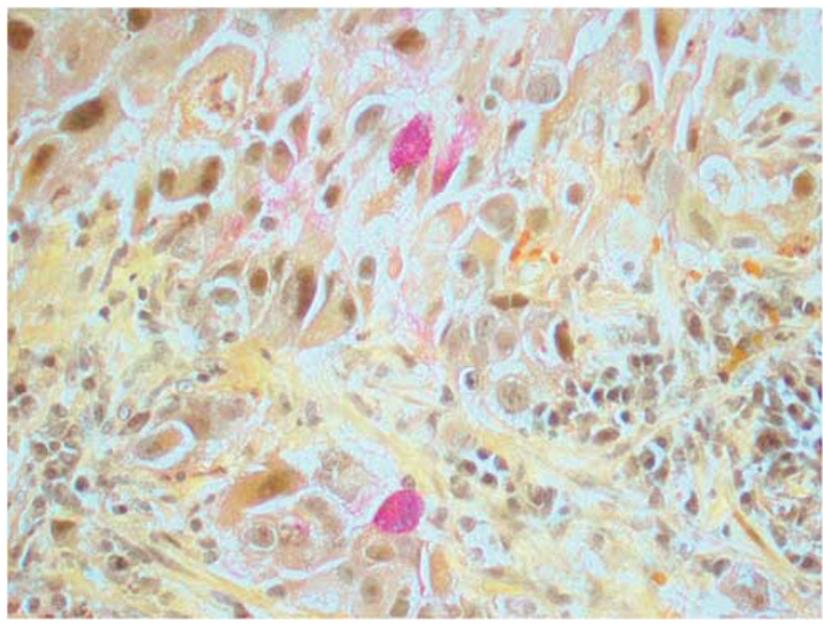

Figure 6 Mucicarmine stain highlighting signet-ring cells $(\times 40)$.

smoker woman. All five patients had high stage disease at presentation. To our knowledge, this is the first report of a woman with hepatoid adenocarcinoma of the lung. She is alive 9 years after presentation with stage IV disease (T1a, No and M1b). The superficial location of her costosternal metastasis was an optimal target for radiation therapy and completely resolved after treatment.

Ishikura et $a l^{1}$ defined hepatoid adenocarcinoma of lung as adenocarcinoma with typical acinar or papillary features and a component of carcinoma that resembles hepatocellular carcinoma and produces AFP. Later reports described hepatoid adenocarcinoma of lung with components of neuroendocrine carcinoma instead of adenocarcinoma. ${ }^{11,16}$ Unlike prior reports, the tumors in the current study were either pure hepatoid adenocarcinoma (three cases) or hepatoid adenocarcinoma with components of signet-ring cells (two cases).
Although two of the current cases did not express AFP, morphology and immunophenotype were consistent with hepatoid adenocarcinoma of lung.

As anticipated, immunohistochemical stains failed to detect ALK protein in both heavy smokers who had tumors with signet-ring cell components. ALK rearrangements usually occur in never or light smokers with signet-ring cell adenocarcinomas that lack EGFR and KRAS mutations. ${ }^{19}$ ALK protein is expressed at lower levels in ALK-rearranged adenocarcinoma of lung than in anaplastic large-cell lymphoma (ALCL) and requires a sensitive monoclonal antibody for detection. ${ }^{20}$ The monoclonal antibody ALK1 (D9E4), originally developed to detect ALK protein in ALCL, is adequate to detect higher levels of ALK protein in ALCL, but has poor sensitivity for detection of lower levels of ALK protein in ALKrearranged adenocarcinoma of lung. According to accounts in the literature, the sensitivity of D9E4 ranges from 40 to $67 \% .{ }^{19,20}$ The monoclonal antibody D5F3 has excellent sensitivity (100\%) and specificity (99\%) for detection of ALK protein in ALK-rearranged adenocarcinoma of lung but is currently available for research use only. ${ }^{20}$

The morphologic features of hepatoid adenocarcinoma of lung are remarkably similar to hepatocellular carcinoma. Exclusion of metastatic hepatocellular carcinoma was clinically relevant because both hepatitis C patients were at risk to develop hepatocellular carcinoma and lung is the most common site for extrahepatic metastasis. ${ }^{21}$ However, CT scans showed no liver masses in both hepatitis $C$ patients and the immunophenotypic signature was inconsistent with hepatocellular carcinoma (Table 2). Hepatoid adenocarcinoma of lung expresses napsin A (1/5), the EpCAM markers HEA125 (5/5) and MOC31 (5/5) and a variety of cytokeratins including CK5/6 (1/5), CK7 (3/5), CK8 (5/5), CK18 (5/5), CK19 (4/5) and CK20 (1/5). Hepatocellular carcinoma does not express napsin A and the EpCAM markers and the only cytokeratins that contribute to intermediate filament formation are CK8 and CK18. Immunostains carried out with monoclonal CEA localized to the cytoplasm and membrane in $3 / 5$ cases of hepatoid adenocarcinoma of lung. Hepatocellular carcinoma does not stain with monoclonal CEA but does show a canicular staining pattern with polyclonal CEA.

TTF-1 immunostains localize to the cytoplasm in both hepatocellular carcinoma and hepatoid adenocarcinoma of lung, unlike nuclear localization in conventional adenocarcinoma of lung, thyroid carcinoma and neuroendocrine carcinoma. Cytoplasmic TTF-1 staining in hepatocytes is due to a crossreacting epitope on a cytoplasmic protein with a molecular weight of $160000 .^{22}$ Expression of this crossreacting cytoplasmic protein in hepatoid adenocarcinoma of lung and hepatocellular carcinoma suggests that it contributes to maintenance of the hepatic phenotype in both tumors.

AFP levels, provided in 12 of 16 prior reports of hepatoid adenocarcinoma of lung (Table 1), were 
Table 3 Clinical features of previous and current cases of hepatoid adenocarcinoma of the lung

\begin{tabular}{|c|c|c|c|c|c|c|c|c|c|}
\hline Author & $\begin{array}{c}\text { Age } \\
\text { (years) }\end{array}$ & Gender & Location & Size $(\mathrm{cm})$ & Smoker & $\begin{array}{l}\text { AFP level } \\
(\mathrm{ng} / \mathrm{ml})\end{array}$ & Stage & Progression & Treatment \\
\hline Arnould et $a l^{9}$ & 36 & Male & Left Upper Lobe & 10.0 & Yes & 11,600 & pT4 N2 & Brain metastasis & $\begin{array}{l}\text { Neoadjuvant } \\
\text { chemotherapy, surgery }\end{array}$ \\
\hline Yasunami et $a l^{4}$ & 67 & Male & Left Upper Lobe & 'Fist-sized' & N/A & 19000 & pT3 N2 & $\begin{array}{l}\text { Rib and vertebra } \\
\text { metastases }\end{array}$ & $\begin{array}{l}\text { Radiation, } \\
\text { immunotherapy (BCG) }\end{array}$ \\
\hline Miyake et $a l^{6}$ & 73 & Male & Left Upper Lobe & $5.0 \times 6.0 \times 5.0$ & N/A & 1039 & pT2b N2 & $\begin{array}{l}\text { Mediastinal, lymph } \\
\text { node, brain metastases }\end{array}$ & $\begin{array}{l}\text { Surgery, postop } \\
\text { radiation }\end{array}$ \\
\hline Kim et $a l^{17}$ & 49 & Male & Left Upper Lobe & 6.0 & N/A & 14707 & pT2b N1 & Not reported & Surgery \\
\hline Iino et $a l^{14}$ & 63 & Male & Right Upper Lobe & $2.8 \times 2.5$ & N/A & N/A & cT1 NO MO & $\begin{array}{l}\text { No progression } 5 \\
\text { months after surgery }\end{array}$ & Surgery \\
\hline Genova $^{13}$ & 71 & Male & Left Upper Lobe & $7.7 \times 6.4$ & N/A & Not assayed & pT3 NO & $\begin{array}{l}\text { No progression at } 24 \\
\text { months }\end{array}$ & Surgery \\
\hline Miyake et $a l^{5}$ & 40 & Male & Right Upper Lobe & $8.0 \times 9.0 \times 7.0$ & N/A & 3090 & pT3 M1b & Not applicable & Surgery \\
\hline Miyake et $a l^{5}$ & 55 & Male & Right Upper Lobe & 5.0 & N/A & 2123 & pT2a Mlb & Not applicable & Surgery \\
\hline Yokoyama et al ${ }^{3}$ & 69 & Male & Right Lower Lobe & $11.0 \times 11.0 \times 7.0$ & N/A & 5050 & pT3 Mlb & Not applicable & N/A \\
\hline Carlifante et $a l^{10}$ & 82 & Male & Left Lower Lobe & 3.5 & Yes & Not assayed & cT2a NO MO & $\begin{array}{l}\text { No progression } 7 \text { years } \\
\text { after surgery }\end{array}$ & Surgery \\
\hline Okunaka et $a l^{7}$ & 49 & Male & Right Upper Lobe & $6.0 \times 5.0 \times 5.0$ & N/A & 9300 & cT3 & $\begin{array}{l}\text { No progression at } 11 \\
\text { months }\end{array}$ & Surgery \\
\hline Nasu et $a l^{8}$ & 63 & Male & Right Upper Lobe & $14.0 \times 13.0 \times 12.0$ & N/A & 14000 & cT4 N2 & $\begin{array}{l}\text { Lung, right adrenal } \\
\text { gland, brain metastases }\end{array}$ & Chemotherapy \\
\hline Oshiro et al ${ }^{15}$ & 77 & Male & Right Lower Lobe & Not reported & N/A & Not assayed & cT2 NO MO & Liver metastasis & Surgery \\
\hline Hayashi et al ${ }^{12}$ & 55 & Male & Right Upper Lobe & $5.0 \times 4.8 \times 6.5$ & Yes & 89 & pT2b NO & $\begin{array}{l}\text { No progression at } 32 \\
\text { months }\end{array}$ & Surgery \\
\hline Hiroshima et al ${ }^{11}$ & 71 & Male & Right Lower Lobe & $10.5 \times 8.5 \times 7$ & Yes & 7417 & pT3 NI & $\begin{array}{l}\text { Lung and brain } \\
\text { metastases }\end{array}$ & Surgery \\
\hline Kishimoto et al ${ }^{16}$ & 64 & Male & Left Lower Lobe & $7.5 \times 7.0 \times 4.0$ & N/A & 673 & cT3 NO MO & Not reported & Surgery \\
\hline Current Case 1 & 51 & Male & Right Upper Lobe & $4.2 \times 3.7$ & Yes & $1.3^{\mathrm{a}}$ & cT2a N3 MO & $\begin{array}{l}\text { Died } 14 \text { months after } \\
\text { presentation }\end{array}$ & $\begin{array}{l}\text { Chemoradiation, tumor } \\
\text { debulking }\end{array}$ \\
\hline Current Case 2 & 52 & Male & Right Upper Lobe & 2.5 & Yes & Not assayed & cT1b NO M1b & $\begin{array}{l}\text { Not applicable; alive } 37 \\
\text { months after } \\
\text { presentation }\end{array}$ & $\begin{array}{l}\text { Surgery, postop } \\
\text { chemoradiation }\end{array}$ \\
\hline Current Case 3 & 64 & Male & Left Upper Lobe & $3.2 \times 2.2$ & Yes & $1.0^{\mathrm{a}}$ & cT2a NO M1b & $\begin{array}{l}\text { Not applicable; died } 10 \\
\text { months after } \\
\text { presentation }\end{array}$ & $\begin{array}{l}\text { Surgery, postop } \\
\text { chemoradiation }\end{array}$ \\
\hline Current Case 4 & 54 & Female & Left Upper Lobe & 1.0 & Yes & Not assayed & cT1a No M1b & $\begin{array}{l}\text { Not applicable; alive } 9 \\
\text { years after presentation }\end{array}$ & $\begin{array}{l}\text { Chemoradiation, tumor } \\
\text { debulking }\end{array}$ \\
\hline Current Case 5 & 60 & Male & Right Upper Lobe & $11.2 \times 10.1 \times 8.5$ & Yes & $4410^{\mathrm{b}}$ & cT3, N2, M1b & $\begin{array}{l}\text { Not applicable; alive } 1 \\
\text { month after presentation }\end{array}$ & Chemoradiation \\
\hline
\end{tabular}

\footnotetext{
${ }^{\mathrm{a} A f t e r}$ treatment.

bretreatment.
} 
markedly elevated in all 12 patients. ${ }^{3-9,11,12,16,17}$ AFP immunoassays, ordered by clinicians in three of five current cases, showed marked elevation of serum AFP in one patient $(4410 \mathrm{ng} / \mathrm{ml})$. A normal AFP level was concordant with the negative immunohistochemical stain for AFP in one case. The AFP level was within normal limits at $1 \mathrm{ng} / \mathrm{ml}$ in one case with positive AFP immunostaining. However, the immunoassay for AFP was carried out after the patient underwent surgical resection of a bulky vertebral body metastasis followed by postoperative chemoradiation therapy. Significant reduction of tumor volume after multimodality therapy accounted for discordance between AFP expression in pretreatment tumor tissue and normal post-treatment serum AFP level.

About $50 \%$ of cases of conventional adenocarcinoma of lung harbor somatic mutations in genes that encode proteins in the EGFR signaling pathway: K-RAS, EGFR, HER2, HER4, BRAF and PIK3CA. ${ }^{23}$ Although EGFR mutations were unlikely in our cohort of four heavy smoker men and one heavy smoker woman, medical oncology hoped to treat one patient with comorbid conditions with a tyrosine kinase inhibitor and tested for EGFR mutation. As anticipated, there was no EGFR mutation, so the only treatment option was conventional chemotherapy.

Demographics and immunohistochemistry facilitate selection of patients with adenocarcinoma of lung more likely to harbor EGFR mutations. EGFR mutations are well known to occur more frequently in young Asian women without a smoking history. Strong Allred immunohistochemical scores for the $\mathrm{ER} \beta$ correlate positively with EGFR mutations in adenocarcinoma of lung. ${ }^{24}$ The Allred scores for $\operatorname{ER} \beta$ were weak in four of five cases of hepatoid adenocarcinoma of lung, an indication that EGFR mutations were unlikely. Although one case had a strong Allred score, EGFR mutation was unlikely in a heavy smoker.

Hepatoid adenocarcinoma of lung is a rare tumor with male gender predilection and morphologic features similar to hepatocellular carcinoma. Determination of site of origin for hepatoid adenocarcinoma of lung can be difficult in patients with both lung and liver masses and in patients at risk for lung and liver cancer because of smoking and viral hepatitis, respectively, which was the clinical scenario for two patients in this report. Distinguishing hepatoid adenocarcinoma of lung from metastatic hepatocellular carcinoma requires radiologic, morphologic and immunophenotypic correlation. On the basis of current and prior observations, we propose modification of Ishikura's diagnostic criteria $^{1}$ for hepatoid adenocarcinoma of lung: (1) The tumor can be pure hepatoid adenocarcinoma or have components of typical acinar or papillary adenocarcinoma, signet-ring cells or neuroendocrine carcinoma and (2) AFP expression is not mandatory for diagnosis as long as other markers of hepatic differentiation are expressed.

\section{Acknowledgements}

We are grateful to Dr Anthony Janckila at the Robley Rex VAMC in Louisville, KY for editorial comments. We thank Mrs Mary Williams for preparation of the manuscript.

\section{Disclosure/conflict of interest}

The authors declare no conflict of interest.

\section{References}

1 Metzgeroth G, Strobel P, Baumbusch T, et al. Hepatoid adenocarcinoma-review of the literature illustrated by a rare case originating in the peritoneal cavity. Onkologie 2010;33:263-269.

2 Ishikura H, Kanda M, Ito M, et al. Hepatoid adenocarcinoma: a distinctive histological subtype of alphafetoprotein-producing lung carcinoma. Virchows Arch A 1990;417:73-80.

3 Yokoyama K, Morimoto H, Kaito T, et al. An autopsied case of alpha-fetoprotein (AFP) producing large cell carcinoma of the lung. Jpn J Thorac Surg 1981;34: 609-612.

4 Yasunami R, Hashimoto Z, Ogura T, et al. Primary lung cancer producing alpha-fetoprotein: a case report. Cancer 1981;47:926-929.

5 Miyake M, Ito M, Taki T, et al. A case report of two patients with primary lung cancer secreting AFP. J Jpn Assoc Thorac Surg 1986;34:914-919.

6 Miyake M, Ito M, Mitsuoka A, et al. Alpha-fetoprotein and human chorionic gonadotropin-producing lung cancer. Cancer 1987;59:227-232.

7 Okunaka T, Kato H, Konaka C, et al. Primary lung cancer producing $\alpha$-fetoprotein. Ann Thorac Surg 1992;53:151-152.

8 Nasu M, Soma T, Fukushima H, et al. Hepatoid carcinoma of the lung with production of $\alpha$-fetoprotein and abnormal prothrombin: an autopsy case report. Mod Pathol 1997;10:1054-1058.

9 Arnould L, Drouot F, Fargeot P, et al. Hepatoid adenocarcinoma of the lung: report of a case of an unusual [alpha]-fetoprotein-producing lung tumor. Am J Surg Pathol 1997;21:1113-1118.

10 Carlinfante G, Pia Foschini M, Pasquinelli G, et al. Hepatoid carcinoma of the lung: a case report with immunohistochemical, ultrastructural and in situ hybridization findings. Histopathology 2000;37:85-94.

11 Hiroshima K, Iyoda A, Toyozaki T, et al. Alpha-fetoprotein-producing lung carcinoma: report of three cases. Pathol Int 2002;52:46-53.

12 Hayashi Y, Takanashi Y, Ohsawa H, et al. Hepatoid adenocarcinoma in the lung. Lung Cancer 2002;38: 211-214

13 Genova S. Hepatoid adenocarcinoma of the lung: a case report. Internet J Pathol 2002;2:1-5.

14 Iino $\mathrm{K}$, Ohta $\mathrm{Y}$, Tamura $\mathrm{M}$, et al. A resected case of alpha-fetoprotein-producing hepatoid adenocarcinoma of the lung. Jpn J Lung Cancer 2003;43: 29-34.

15 Oshiro Y, Takada Y, Enomoto T, et al. A resected case of metachronous liver metastasis from lung cancer producing alpha-fetoprotein (AFP) and protein 
induced by vitamin $\mathrm{K}$ absence or antagonist II (PIVKAII). Hepatogastroenterology 2004;51:1144-1147.

16 Kishimoto T, Yano T, Hiroshima K, et al. A case of $\alpha$-fetoprotein-producing pulmonary carcinoma with restricted expression of hepatocyte nuclear factor- $4 \alpha$ in hepatoid foci: a case report with studies of previous cases. Hum Pathol 2008;39:1115-1120.

17 Kim L, Song JY, Jin X, et al. Hepatoid adenocarcinoma arising in the lung: a case report. Bas Appl Path 2009;2:A47.

18 Allred DC, Harvey JM, Berardo MD, et al. Prognostic and predictive factors in breast cancer by immunohistochemical analysis. Mod Pathol 1998;11:155-168.

19 Rodig SJ, Mino-Kenudson M, Dacic S, et al. Unique clinicopathologic features characterize ALK-rearranged lung adenocarcinoma in the western population. Clin Cancer Res 2009;15:5216-5223.

20 Mino-Kenudson M, Chirieac LR, Law K, et al. A novel, highly sensitive antibody allows for the routine detec- tion of ALK-rearranged lung adenocarcinomas by standard immunohistochemistry. Clin Cancer Res 2010;16:1561-1571.

21 Uka K, Aikata H, Takaki S, et al. Clinical features and prognosis of patients with extrahepatic metastases from hepatocellular carcinoma. World J Gastroenterol 2007;13:414-420.

$22 \mathrm{Gu} \mathrm{K}$, Shah V, Ma C, et al. Cytoplasmic immunoreactivity of thyroid transcription factor-1 (clone 867G3/ 1) in hepatocytes. True positivity or cross-reaction. Am J Clin Pathol 2007;128:382-388.

23 Ding L, Getz G, Wheeler DA, et al. Somatic mutations affect key pathways in lung adenocarcinoma. Nature 2008;455:1069-1075.

24 Nose N, Sugio K, Oyaama T, et al. Association between estrogen receptor- $\beta$ expression and epidermal growth factor receptor mutation in the postoperative prognosis of adenocarcinoma of the lung. J Clin Oncol 2009;27: 411-417. 